\title{
PR and Hysteresis Controlled PV fed Cascaded Boost ReBoost Inverter Systems
}

\author{
T. R. Premila, R. Krishna Kumar
} is also one of the most authentic methods. This explains about the Proposed Resonant and Hysteresis control of cascaded boost-re-boost-inverter system with PV as source. The simulation for Cascaded-Boost-Re-Boost-Inverter-System (CBR-BIS) is done using Simulink and cascaded-loop-investigations are performed with PR \& Hysteresis-Controllers. Results of CBR-BIS systems like rise-time, settling-time and steady-state error are taken.The objectives of this work are Maximum-Power-achievement and low-voltage-regulation of CBR-BIS. The outcomes represent that utmost-power is attained with low--speed-regulation using HC-controller.

\section{Keywords : Hysteresis controller, PR controller}

\section{INTRODUCTION}

Solar energy is gaining popularity in the field of electricity generation. The benefits of solar power such as no air pollution, no fuel cost noiseless and less maintenance [1-3]. In this work solar energy is considered as a input. Here two closed loops are used. One closed loop is used for to achieve maximum power point. In this closed loop the constant voltage MPPT algorithm with boost converter is used to track the maximum power point. Another closed loop is voltage regulation loop. In this loop re-boost converter is used to maintain constant voltage. Benefits of using converters are soft switching, switching losses are very less and electromagnetic interference are also reduced. The boost and re-boost combination technique is very new one. The advantage of using re-boost converter circuit high voltage are used. In renewable energy source the solar energy technology development is most impartment issues[4-5].To increase the productivity and get higher voltage gain with $\mathrm{dc}$ to dc converter controlled MPPT is imparted[6-10].

\section{RESEARCH GAP}

The exceeding-literature does not deal with combination of boost and Re-boost converters. This effort recommends cascaded-boost and Re-boost-converter to enhance the

Revised Version Manuscript Received on 16 September, 2019.

* Correspondence Author

T.R.Premila EEE Department, Vels Institute Of Science, Technology And Advanced Studies, Chennai, India. Email: trpremilashaji@gmail.com

Dr.R.Krishna Kumar, Professor/Head EEE Department, Vels Institute Of Science, Technology And Advanced Studies, Chennai, India. Email: hodeee@velsuniv.ac.in
Abstract:Speed-regulation using hysteresis-controller framework gain is possible because of two inductors and two capacitors

voltage -gain. These exceeding work do not recommend combination of MPPT and voltage-control using PR or HC to enhance dynamic-characteristics of BRBCI-system. This work proposes combined MPPT-Hysteresis Controller to improve the time-response of BRBCIS and achieve maximum power at the output

\section{PR CONTROLLER}

If the error signal is very low the PR controller amplify the signal to high value, this is because of the high gain of PR controller. It works on the principle of parallel resonance.PR Controller provides a gain at a certain frequency (resonant frequency) and has almost no gain that exists at other frequencies. This controller does not suffer from the same problem as the PI controller whereby it has the inability to keep track of the sinusoidal reference but has a current controller which is more suitable at operating with the sinusoidal references losses. Circuit Transfer function $=\mathrm{kp}+$ $(\omega / \mathrm{s} 2+\omega 2)$ based on the imaginary root output oscillates with this frequency

\section{HYSTERESIS CONTROLLER}

The hysteresis current control scheme is the simplest and most extensively used technique . It is used to protect the converter and load limits are applied to the load current . Figure1.explains the principle of operation of hysteresis current controller. The control circuit generate reference current for a desired magnitude and it is compared with the actual current. The resulting current error is fed to the hysteresis current controller to determine the gating signals for the switches of the converter . when the current error exceeds the upper limit of the hysteresis band the upper switch is on. On the other hand if the current error crosses the lower limit of the hysteresis band the upper switch of the phase leg is on and lower switch is off.

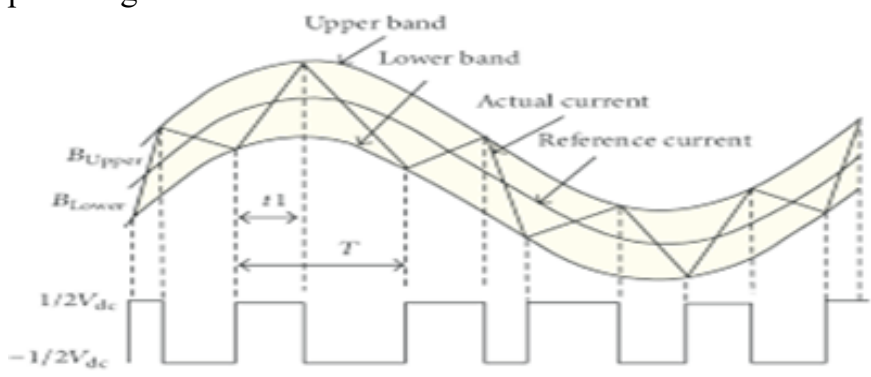

Fig.1. Hysteresis current control 
Hysteresis Controller is PI Controller with limiter. The PI Controller $\mathrm{Kp}$ and $\mathrm{Ki}$, are determined by using Zigler Ni chol's tuning method where $\mathrm{K}_{\mathrm{p}}=\zeta / \mathrm{T}: \mathrm{K}_{\mathrm{i}}=1.5 * \mathrm{~T}$

\section{SYSTEM CONFIGURATION}

The block-diagram of open-loop CBRBIS appeared in Fig-2 that consists of the PV, Boost converter, Re-boost-converter, Inverter \&load. The block diagram of Closed-loop CBRBIS PR and HC-system is appeared in Fig-3 andFig-4.Constant power MPPT method is used. The voltage of PV is compared with the reference. Voltage and the error is applied to PRC and hysteresis controller. The output of controller updates the pulse width of BC. The motor speed is sensed and it is compared with reference speed and speed error is applied to $\mathrm{PRC} / \mathrm{HC}$ to update pulse width of $\mathrm{RBC}$.

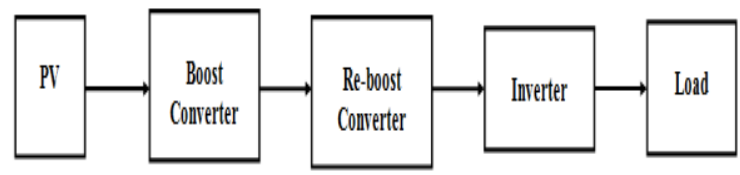

Fig-2. Block Diagram of Open-Loop CBRBIS

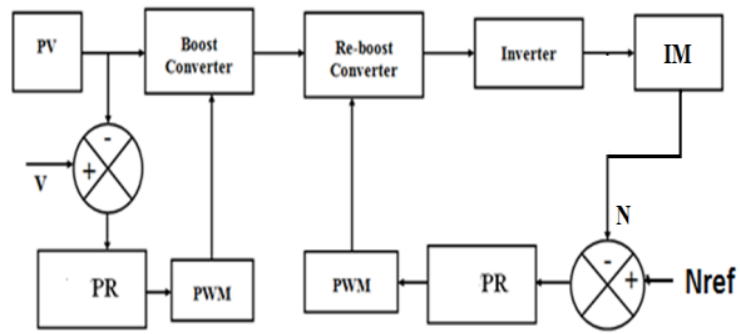

Fig-3. Block Diagram of closed-Loop CBRBIS of PR

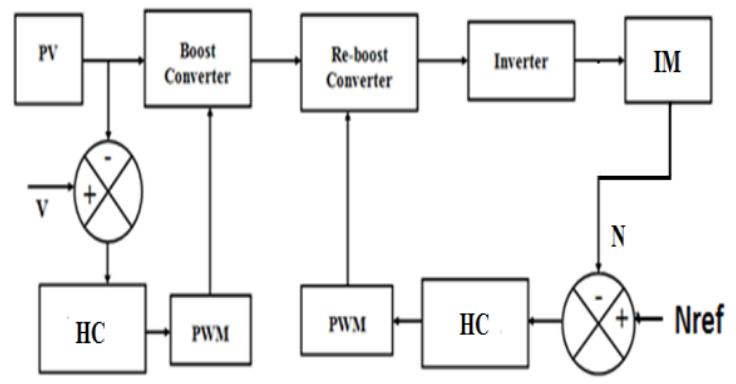

Fig-4. Block Diagram of closed-Loop CBRBIS of HC

\section{The modeling of CBRBIS is as follows:}

The torque developed by SPIM is as follows:

$$
\mathrm{T}_{\mathrm{de}}=\mathrm{KI}^{2}(1 / \mathrm{s}-1 /(2-\mathrm{s})) \text {. }
$$

Max. power $=\mathrm{V}_{\mathrm{mp}} * \mathrm{I}_{\mathrm{mp}}$

The transfer-function of PR is as follows:

T.F. $=\mathrm{w} /\left(\mathrm{s}^{2}+\mathrm{w}^{2}\right)$
The upper and lower limits of $\mathrm{HC}$ are calculated asfollows:

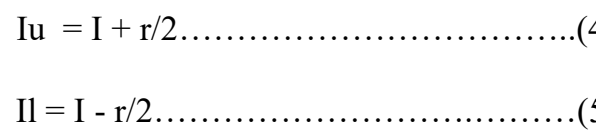

Where $\mathrm{r}$ is the ripple-current

$\mathrm{r}=\mathrm{Iu}-\mathrm{Il}$

Speed-error $=$ Nref- $\mathrm{N}$

\section{SIMULATION RESULTS}

\section{A OPEN LOOP CBRBIS WITH DISTURBANCE}

Circuit diagram of open-loop CBRBIS with disturbance is depict in Fig-5.Voltage across PV is depict in Fig-6 and its value is $44 \mathrm{~V}$. The fall in output voltage is due to fall in irradiation. Voltage-across DC-load of BRBIS is depict in Fig-7\&its value is $80 \mathrm{~V}$.Current through DC load of BRBIS is depict in Fig- 8 \&its value is $0.16 \mathrm{~A}$. The Fall in output current is due to fall in irradiation.Voltage across Reboost-converter of CBRBIS is depict in Fig-9 and its value is $249 \mathrm{~V}$. Motor-speed is depict in Fig-10 and its value is 1200RPM.Motor-torque is delpict in Fig-11and its value is $4 \mathrm{~N}-\mathrm{m}$. The voltage across RBC and motor speed decreases due to the fall in the PV voltage.

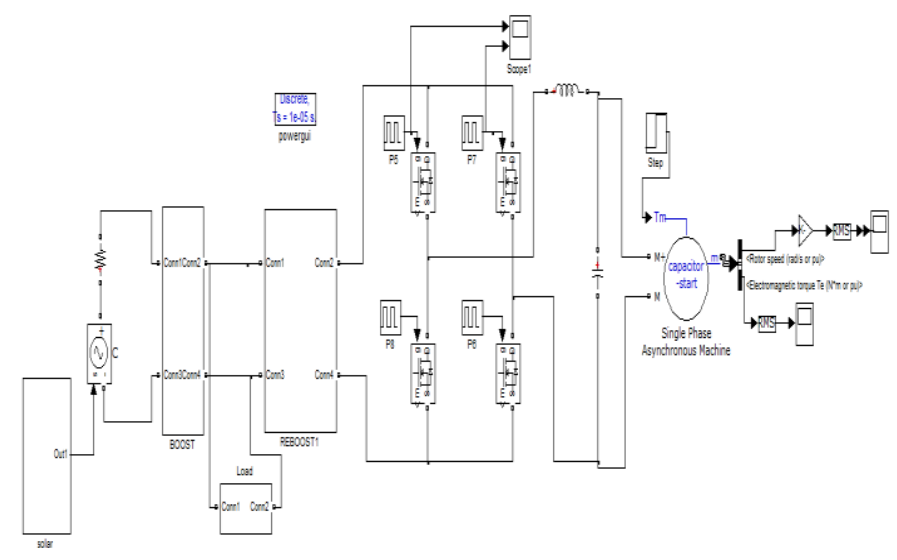

Fig 5. Circuit diagram of Open-loop CBRBIS with voltagedisturbance

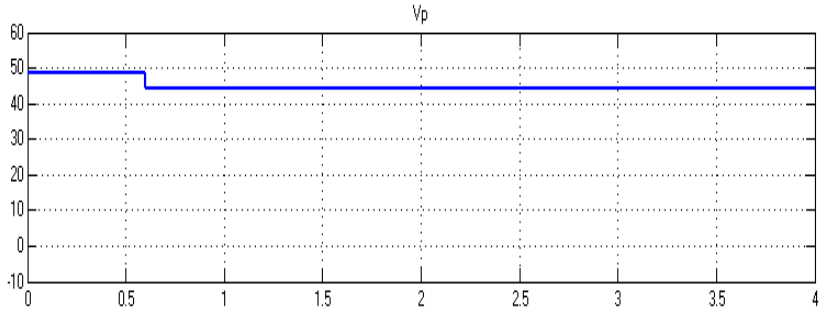

Fig 6. Voltage Across PV 


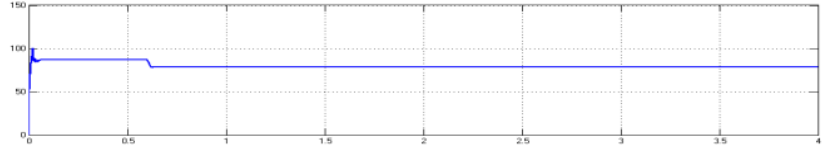

Fig 7. Voltage across DC load

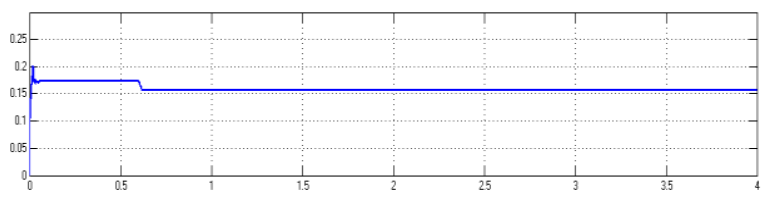

Fig 8. Current through DC load

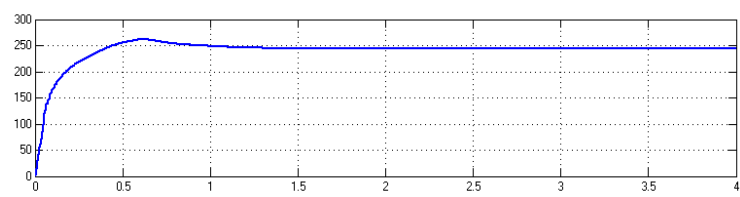

Fig 9. Voltage across Reboost

Fig 10. Motor speedof Open-loop CBRBIS

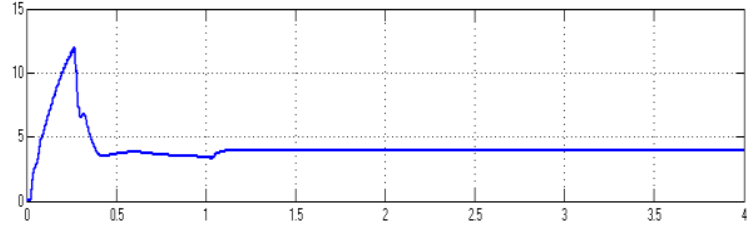

Fig 11. Motor Torqueof Open-loop CBRBIS

\section{B CLOSED LOOP CBRBIS WITH MPPT AND PRC}

Circuit diagram of PRC- CBRBIS is depict in Fig-12. Voltage-across DC-loadof PRC-CBRBIS is depict in Fig-13 \&its value is $80 \mathrm{~V}$. The output voltage is regulated using PR controller. Current through DC loadof PRC-CBRBIS is depict in Fig-14\&its value is 0.17A.The current is regulated by using PR controller.Voltage across Reboost-converter of PRC-CBRBIS is depict in Fig-15\&its value is $310 \mathrm{~V}$. Motor-speed of PRC-CBRBICS is depict in Fig-16\&its value is 1220RPM. Voltage of RBC is updated and speed is regulated using PR-controller. Motor-torqueof PRC-CBRBIS is depict in Fig-17\&its value is $6 \mathrm{~N}-\mathrm{m}$.
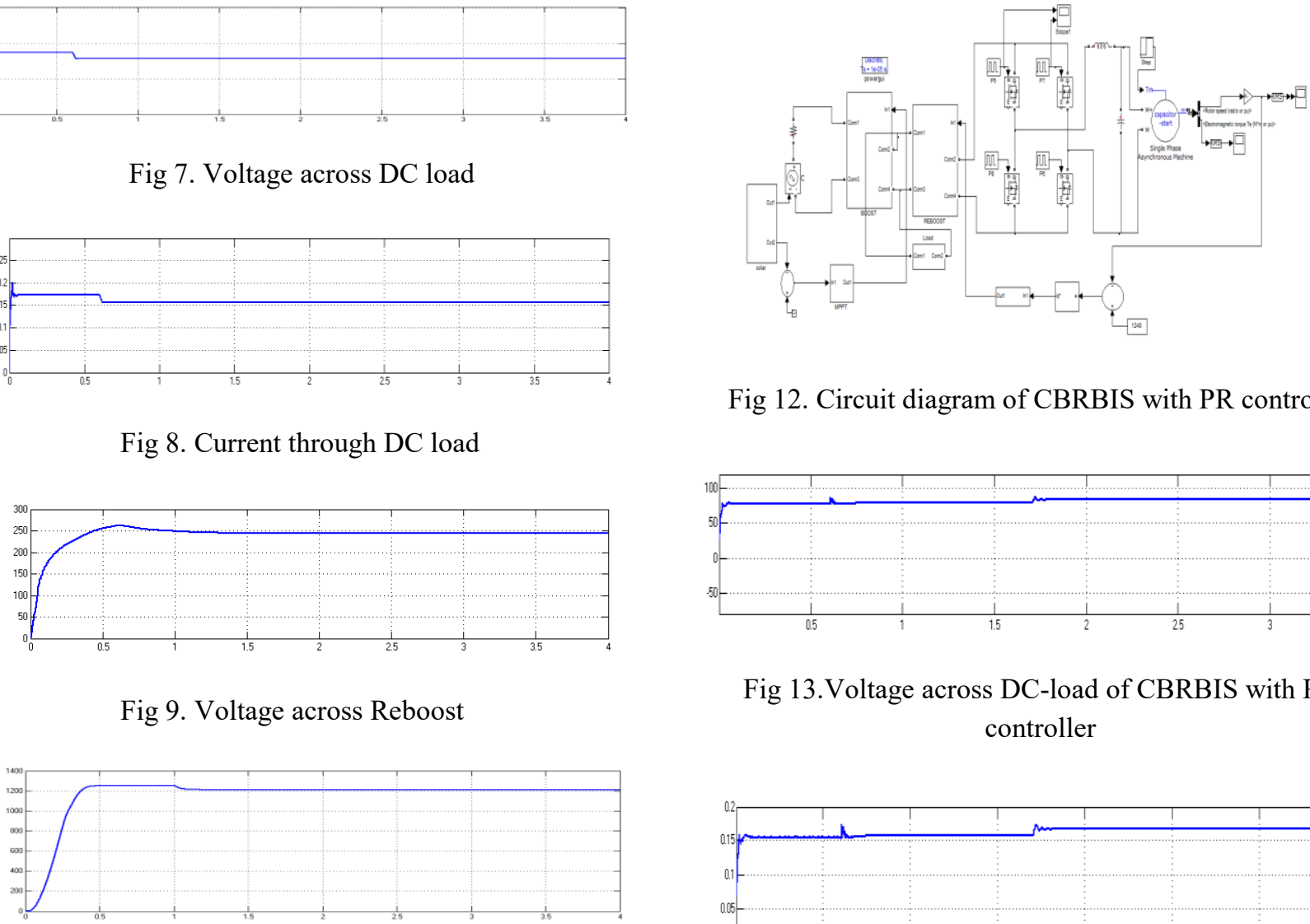

Fig 12. Circuit diagram of CBRBIS with PR controller

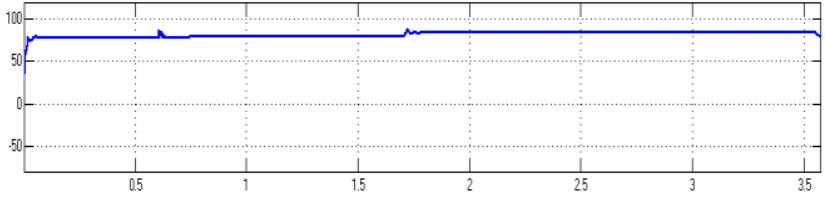

Fig 13.Voltage across DC-load of CBRBIS with PR controller

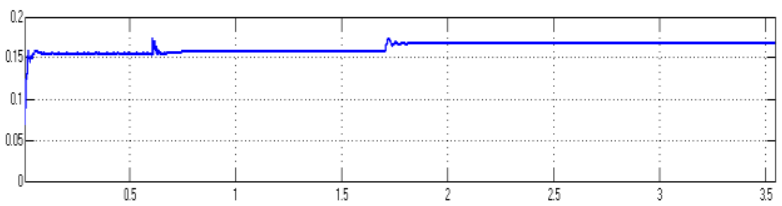

Fig 14.Current through DC -load of CBRBIS with PR controller

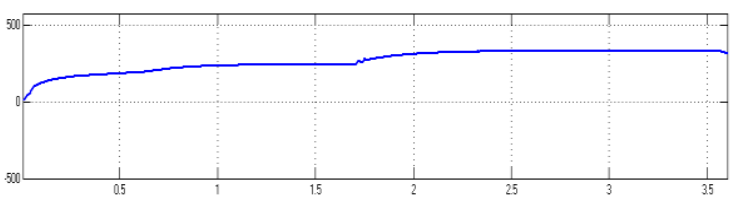

Fig 15.voltage across Reboost converter of CBRBIS with PR controller

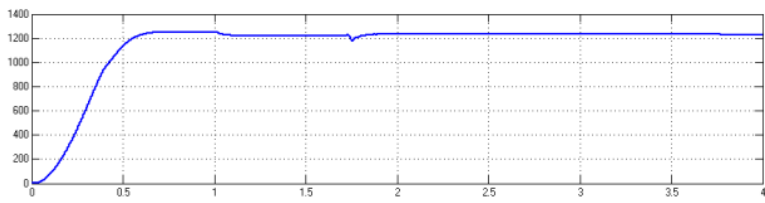

Fig 16.Motor speed of CBRBIS with PR controller

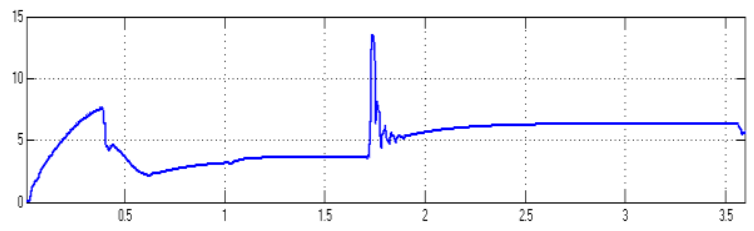


Fig 17.Motor torque of CBRBIS with PR controller

\section{CLOSED LOOP CBRBIS WITH HC AND MPPT}

Circuit diagram of CBRBIS with $\mathrm{HC}$ is depict in Fig-18. Voltage-across DC-load of CBRBIS with HC is depict in

Fig-19\&its value is 80V.Current through DC loadof CBRBIS with $\mathrm{HC}$ is depict in Fig-20\&its value is 0.17A.The current reduces and reaches normal value due to $\mathrm{HC}$. Voltage across Reboost-converter of CBRBIS with HC is depict in Fig-21\&its value is $350 \mathrm{~V}$. Motor-speedof CBRBIS with HC is depict in Fig-22\&its value is 1220RPM. Voltage across $\mathrm{RBC}$ is updated and speed of IM is regulated using HC. The response is accelarated using $\mathrm{HC}$. Motor-torque of CLBRBI with Hystsresis-controller is depict in Fig-23\&its value is $6 \mathrm{~N}-\mathrm{m}$.

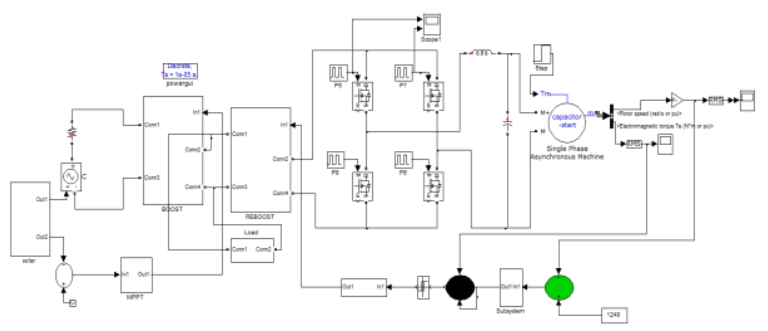

Fig 18Circuit diagram of CBRBIS with hysteresis controller

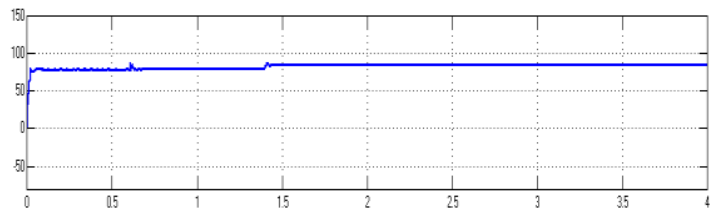

Fig 19Voltage across DC-load of CBRBIS of HC

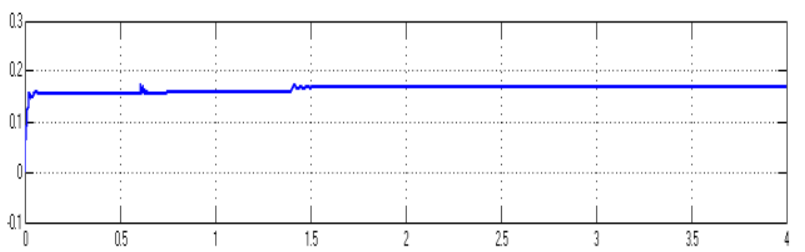

Fig20 Current through DC load of CBRBIS of HC

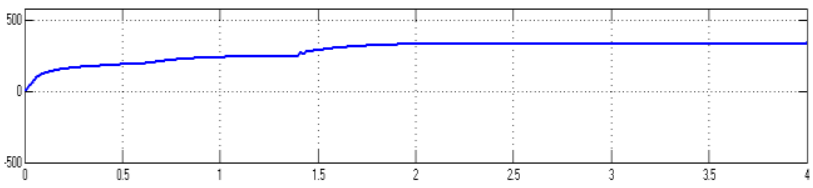

Fig 21voltage across reboost converter of CBRBIS of HC

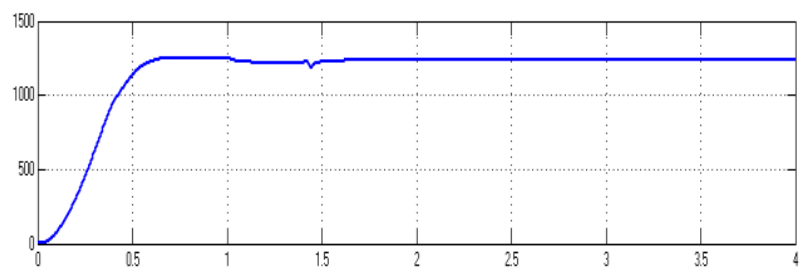

Fig 22Motor speed of CBRBIS of HC

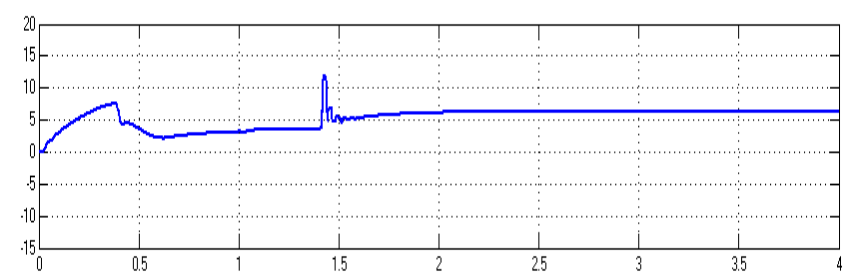

Fig 23Motor torque of CBRBIS of HC

Comparison of time-domain-parameters of CBRBIS with PR and $\mathrm{HC}$ are given in table-1. By using Hysteresis controller, the rise-time is diminished from $1.03 \mathrm{Sec}$ to $1.02 \mathrm{Sec}$; Settling-time is diminished from $1.84 \mathrm{Sec}$ to $1.50 \mathrm{Sec}$;Peaktime is diminished from $1.75 \mathrm{Sec}$ to $1.45 \mathrm{Sec}$;Steady-state-error is diminished from 0.03 to 0.02RPM.Comparison of output voltage with MPPT without MPPT is given in table-2.By utilizing MPPT, output-voltage is enhanced from $205 \mathrm{~V}$ to $230 \mathrm{~V}$.

TABLE-1COMPARISON OF

TIME-DOMAIN-PARAMETERS OF CBRBIS WITH PR\&HC

\begin{tabular}{|c|c|c|c|c|}
\hline Controller & $\mathbf{T}_{\mathbf{r}}(\mathbf{S e c})$ & $\mathbf{T}_{\mathbf{s}}(\mathbf{S e c})$ & $\mathbf{T}_{\mathbf{p}}(\mathbf{S e c})$ & $\begin{array}{c}\mathbf{E}_{\mathbf{s s}}(\mathbf{R P} \\
\mathbf{M})\end{array}$ \\
\hline $\mathrm{PR}$ & 1.03 & 1.84 & 1.75 & 0.03 \\
\hline $\mathrm{HC}$ & 1.02 & 1.50 & 1.45 & 0.02 \\
\hline
\end{tabular}

Table-2Comparison of output voltage with MPPT without MPPT

\begin{tabular}{|c|c|}
\hline Case & $\mathbf{V}_{\mathbf{o}}$ \\
\hline Without MPPT & $205 \mathrm{~V}$ \\
\hline With MPPT & $230 \mathrm{~V}$ \\
\hline
\end{tabular}

\section{CONCLUSION}

The open loop boost and re-boost inverter system, closed loop boost-re-boost inverter system with PR controller and hysteresis controller is done by MATLAB software. The hardware is designed and experimentally verified. The response results clearly explain hysteresis controller with boost, re-boost converter inverter system gives rated speed. The simulation results illustrated that constant speed could be maintained by using HRC. The outcome represents that the HC-controlled system is having low-steady-state-error and settling- time. MPPT is successfully implemented in PR / HC controller CBRBIS. The contribution of the present work is to achive MPPT and speed regulation simultaneously. This work has the merit of increased gain and low distortion.Analysis of CBRBIS with HC and FLC can be carried out further. 


\section{REFERENCES}

1 J.A.Vieira,A.M.Mota,Maximum power point tracker applied in batteries charging with PVpanels,IEEE-inter..,symposium-on-I.E-(ISIE), pp-202-207,2008

2S.J.Chiang,H.J.Shieh\&M.C.Chen,Modeling\&-control-of-PV-charger-syst em-with-SEPIC -converter,-IEEE-Trans. On-I.E, vol-56, no-11, pp-4344-4353, -2009 .

3H.S.H.Chung,-K.K.Tse, -S.Y.R.Hui, -C.M.Mok\&-M.T.Ho, A-novel-maximum-power-point-tracking-technique-for-solar-panelsusing-a-SEPIC-or-Cuk-converter,IEEE-Trans.-on-P.E,-vol-18,-no- 3, pp-717-724, -2003.

4-M.G.Simoes, \&-N.N.Franceschetti,Fuzzy-optimisation-based-control-of-a -solar-array-system,-IEEE-Trans. On-Power-App, -vol-146, -no-5, pp-552-558, -1999.

5-X.Qi\&-H.Li,-Application-of-fuzzy-logic\&immune-response-feed-back-fo r-PV-generating- System,-Biosciences (BIOSCIENCES-WORLD), -pp-119-124, -2010.

6-N.Femia,-G.Petrone,-G.Spagnuolo,\&-M.Vitelli,

Optimization-of-perturb\&-observe-maximum-power-point-trackingmethod,- IEEE-Trans. On-P.E, -vol-20,- no-4, -pp- 963-973, -2005.

7-A.Safari\&-S.Mekhilef,-Simulation\&-hardware-implementation-of-incre mental-conductance-mppt-with-direct-control-method-using-Cu $\sigma \circ \mathrm{k}$ -Converter,-IEEE-trans. On-I.E, -vol-58, -no-4, pp-1154-1161, -2011. 8-Y.S.Lee, -W.Y.Yang

\&-Z.Y.Yang,-Fuzzy-logic-maximum-power-point-tracking-control-fo r-pv-inverter,-ieee .P.E-and-motion-control-conf..,(IPEMC), -vol-3, -pp-2056- 2060, -2012.

9-W.Yu,-C.Hutchens,-J.S.Lai,-J.Zhang, -G.Lisi,-A.Djabbari,-G.Smith, \&-T.Hegarty,

-High-efficiency-converter-with-charge-pump\&-coupled-inductor-for -wide-input-photovoltaic-AC-module- applications,ieee-energy-conversion-congress \&- exposition (ECCE), pp-3895-3900, -2009.

10-R.J.Wai,-C.Y.Lin,-R.Y.Duan,\&Y.R.Chang,

High-efficiency-DC-DC-converter-with-high-voltage-gain

\&-reduced-switch- stress, IEEE-trans. on I.E, vol-54, no-1, pp-354$364,-2007$.

\section{AUTHORS PROFILE}

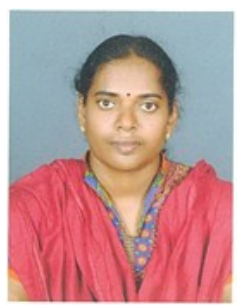

T.R.Premila received B.E degree from the Department of Electrical And Electronics, from Manonmanium Sundernar University,Tamil Nadu, India in 1999. She got ME-Process Control and Instrumentationdegree from Annamalai University, TamilNadu, India in 2001.She is a Part time Research Scholar at Vels Institute of Science Technology And Advanced Studies, Chennai, 600117, Tamil Nadu, India. Her research interest is Solar System, Control System and Power electronics.

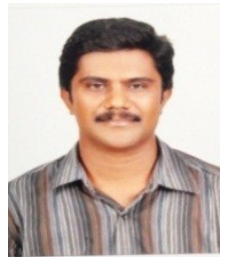

Dr. R. Krishna Kumar received $\mathrm{PhD}$ degree from Anna University, Chennai. He is currently working as a Professor/Head in the department of Electrical and Electronics Engineering, at Vels Institute of Science Technology And Advanced Studies, Chennai, Tamil $\mathrm{Nadu}$, India. He has sixteen years of working experience. He is a member in SAEINDIA.His area of research interest includes Unmanned Aerial Vehicle (UAV) and Power Electronics and Drives 